The text connects five critic presentations of new art works made by brazilian artists (some of them new): Otto Saxinger, Pedro Paulo Domingues, Lia do Rio, Michael Lauss, Monica Mansur, Reinhold Rebhandl, Mônica Mansur, Beatriz Pimenta, Gisele Ribeiro, Cezar Bartholomeu, Amador Perez, Heleno Bernardi e Rômulo Martinz.

Keywords: contemporary art, Brazilian art, art criticism. 


\section{Do Rio, uma rótula}

Roberto

CONDURU

O texto é constituído por cinco apresentações críticas de novas obras e, em alguns casos, também de novos artistas do Brasil: Otto Saxinger, Pedro Paulo Domingues, Lia do Rio, Michael Lauss, Monica Mansur, Reinhold Rebhandl, Mônica Mansur, Beatriz Pimenta, Gisele Ribeiro, Cezar Bartholomeu, Amador Perez, Heleno Bernardi e Rômulo Martinz.

Palavras-chave: arte contemporânea, arte no Brasil, crítica de arte. 
Entre os desafios da crítica de arte está o de acompanhar a emergência da obra artística. Tenham os artistas uma trajetória maior ou menor, menos ou mais consolidada, reconhecida e respaldada, é sempre estimulante e um tanto arriscado dialogar com um trabalho quando de seu primeiro aparecimento, rompendo juntos o silêncio.

Os textos que seguem nasceram com esse desafio - são apresentações primeiras de novas obras e, em alguns casos, também de novos artistas ao público. Foram produzidos independentemente, a partir do Rio de Janeiro, para folhetos de exposições individuais e coletivas no Rio e em outras cidades. Agora, se encontram em Visualidades, revista da Faculdade de Artes Visuais da Universidade Federal de Goiás. A articulação desses textos nesse outro contexto pretende, assim como as inúmeras rótulas viárias de Goiânia (uma primeira concretização no Brasil central do ideal modernista de cidade, que foi projetada a partir do Rio de Janeiro por Attilio Corrêa Lima), constituir um ponto de encontros e redirecionamentos de obras, textos e leituras, almejando intensificar e manter abertos os fluxos contemporâneos da arte. Do Rio, mais uma rótula para Goiânia.

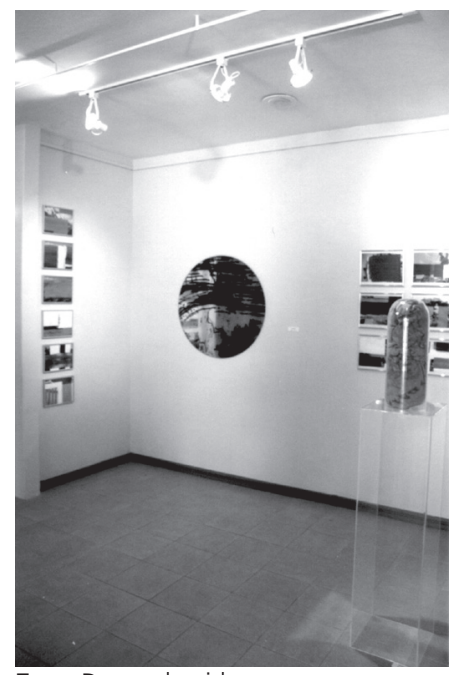

Zona Desconhecida

\section{Zona Desconhecida}

Acesso Remoto não pretende, de modo ingênuo, constituir um circuito alternativo - sintomaticamente, começou em Paris, onde Otto Saxinger e Pedro Paulo Domingues se conheceram e constataram a desconexão entre os artistas da Áustria e do Brasil. O projeto visa mais à ampliação das rotas existentes. A iniciativa destaca-se por partir de um grupo de artistas numa época em que o meio de arte depende mais e mais das demandas de curadores 
e instituições. Sobressai ainda a distância que mantêm dos ideais nacionalistas e da afirmação da cultura das respectivas cidades. O intercâmbio tem as obras de arte como objetos e meios de reflexão; exposições, textos, palestras e debates como modos de conexão.

Criado a partir de um encontro fortuito, o projeto conjuga razão e acaso. Um circuito fechado e circular foi composto com mais 4 artistas: Lia do Rio, Michael Lauss, Monica Mansur e Reinhold Rebhandl. Tendo Otto e Pedro Paulo como pólos iniciais, as demais posições do círculo foram escolhidas por sorteio, de modo que todos se relacionam com artistas estrangeiros que não conheciam previamente. Cada artista ofereceu um trabalho seu à leitura de outro e elaborou um trabalho a partir da obra de um terceiro. No Rio de Janeiro, os brasileiros expõem suas "matrizes" e os austríacos, suas "impressões"; em Linz, acontece o oposto.

A princípio, poucos verão o projeto por inteiro. Apesar das aproximações, muita estranheza permanecerá. A abertura a outrem revela-se auto-afirmação e processo de transformação: as obras postas inicialmente nesse circuito tornam-se emblemas dos artistas, que, com os novos trabalhos, interpretam o desconhecido e se revêem à luz do outro. Partindo de um imaginário de virtualidades, os artistas instituem presenças que abrem o diálogo ao público e a desdobramentos futuros, criam uma zona desconhecida.

\section{O que faço é música? ${ }^{2}$}

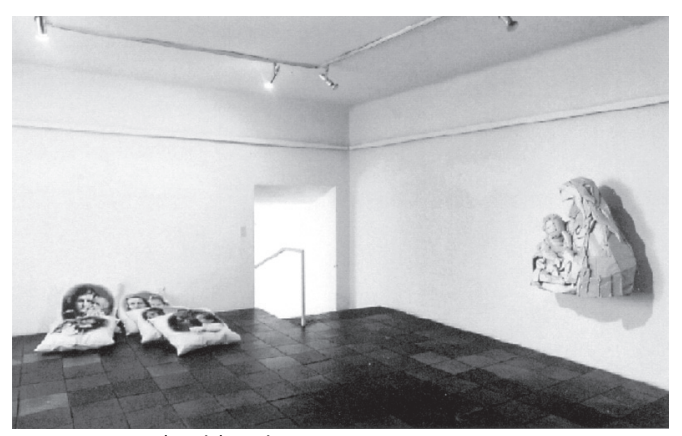

Zona Desconhecida, Linz
De abrigo temporário de obras, a exposição é, há algum tempo, momento e lugar também de criação da arte. Museus, centros culturais e galerias deixaram de ser simples hospe- 
deiros, meros suportes, para tornarem-se, mais do que ateliês ocasionais, elementos ativos da produção artística. Não se trata apenas de fazer uma obra especial para um espaço específico. O desafio para o artista é desdobrar sua pesquisa no lugar, efetivando o encontro entre o trabalho, a instituição e o público. Este, partícipe fundamental do encontro, é chamado a por seu corpo em experiência.

É o que acontece na instalação de Gisele Ribeiro, que se vale do passado residencial e do presente institucional do Castelinho do Flamengo para desenvolver sua pesquisa - Projeto URUBU -, em desdobramento também na Galeria Cândido Portinari - UERJ e, brevemente, na Galeria do Galpão da Pós EBA/UFRJ.

Projeto URUBU: quadro vivo / natureza morta ocupa dois cômodos do edifício e os transforma em ambientes de funções específicas - salas de estar e jantar -, mas sem temporalidade precisa, pois justapõe aos traços ecléticos da casa, móveis e objetos de outras e diferentes épocas. O caráter desses espaços também é ambíguo: superpondo um clima doméstico ao ascetismo da galeria, quer apontar as contaminações entre privado e público no meio de arte e na cultura local. Cenários evidentes, com esses ambientes a artista tanto critica a banalização da instalação como meio artístico quanto instaura um jogo de representação, fazendo-nos cônscios de sermos atores nesse tableau vivant: a cena contemporânea da arte. Ligados, três aparelhos de televisão exibem imagens de urubus: voando na sala de estar, comendo na sala de jantar.

Assim, somos obrigados não só a ver e observar, mas a nos colocar sem grande conforto no lugar dos urubus: voar sobre a carniça, ciscar, bicar e arrastar o bicho morto, engolir a carne em putrefação. Contudo, de pouco adianta recorrer a Goeldi e seus urubus como signos de marginalidade. Gisele segue sim essa trilha romântica, mas seus urubus se querem ao mesmo tempo mais crus e mais distanciados, românticos em sua crítica ao romantismo. Se os móveis no Castelinho, como o saco suspenso com penas na UERJ e o chão de terra na UFRJ, são dados de literalidade, estão longe de pomover, como fazia o artesanato humanista de Goeldi, a comunhão entre os seres nos cantos 
esconsos da cidade periférica. Não há propriamente repulsa ou empatia, nosso confronto com os urubus é mediado pela imagem impávida da tela já domesticada e domesticadora da TV.

Para Beatriz Pimenta a situação não poderia ser mais propícia: ocupar um cômodo de uma casa - tema primeiro e constante de seu trabalho -, caixa onde o corpo se guarda, protege e abastece. Espaço centrado e de simetria quase perfeita com sua planta octogonal e distribuição regular de vãos, espécie de microcosmo, laboratório onde dá continuidade à sua pesquisa sobre as mutações do corpo e suas enganadoras aparências. Investigando uma questão fundamental do classicismo - o corpo, seu equilíbrio e perfeição - e a levando ao paroxismo com suas imagens totalmente simétricas, rígidas e artificiais, a artista filia-se à crítica ao ideal clássico, o trabalho revela-se eminentemente anticlássico.

Como os quartos de seus primeiros desenhos, essa Sala Invertida também causa uma certa claustrofobia: antes eram perspectivas esconsas a trincar a tranqüilidade doméstica, depois foram cortes, rebatimentos e conseqüentes simetrias absolutas que passaram a deflagrar o sentimento de descompasso dos seres no mundo. Recinto fechado sobre si mesmo, com horizontes restritos: a paisagem já circunscrita dos quartos anteriores contrai-se ainda mais, resume-se à imagem de uma árvore em meio a algumas nesgas altas de arquitetura e céu.

Árvore como as que a artista via da sala de aula na infância, outro ser a sofrer na cultura contemporânea. Corpo de luz morna, mas só, amputado e espelhado a ressoar no recinto. Se em outras situações de sua pesquisa era a água (enchente de lágrimas?) a especular continuamente os corpos dobrados sobre si mesmos, agora são folhas em processo de desidratação, como fios de cabelos a cair diariamente, a evidenciar a degradação incessante dos corpos no tempo. Folhas reunidas, fotografadas, digitalizadas, secionadas, rebatidas, como outras tantas imagens que a artista coleciona e manipula: cômodos, corpos, membros - todo e partes em tensão.

Cezar Bartholomeu dá continuidade ao seu propósito de habitar o fotográfico. Apropriando-se da estrutura física da casa, articula fotografia e arquitetura: veda algumas entradas de luz 
e transforma uma seteira em obturador para revelar o edifício como aparelho fotográfico, o quarto como câmara obscura. Assim, nos propicia o exercício prazeroso de vivenciar a câmera, espaço geralmente negligenciado tanto no ato cotidiano de fotografar como nas abordagens teóricas e históricas da fotografia. Como em outras situações, articula muitos e díspares elementos: duas cadeiras - uma vazia, outra não -, um travesseiro sobre uma delas, muitos formando uma coluna ereta a partir do chão, uma radiografia de abdômen suspensa, um par de mesinhas com carimbos, almofadas e papéis.

Seria fácil ler Brancusi, Donald Judd ou Waltércio Caldas nos travesseiros; o embate cerrado com a história - seja da fotografia, da arte ou da filosofia - é fundamento e constante de seu trabalho. Mais pertinente e potente, a meu ver, é entregarse à penumbra difusa que envolve esses volumes alvos macios; o último Leonilson e o Flávio de Carvalho da Série Trágica poderiam ser chamados à cena. Ativando memórias entranhadas no morar e investindo no fotográfico como lugar da ausência, o artista explora a casa e a fotografia como continentes de espectros. Além de obscura, a câmara é mortuária: confronta os presentes com os corpos que guarda.

O sentimento que exala desses móveis familiares, gastos pelo tempo como a coluna curva na chapa, é de tristeza e dor, diferentemente do tom irônico característico de sua pesquisa. Mas o humor não deixa de marcar presença na frase de um dos carimbos: "seu umbigo como ponto de fuga", que tanto indica os vínculos umbilicais entre a fotografia e a perspectiva, quanto crítica a predominância de poéticas auto-centradas no meio de arte hoje. Ironia que reincide com um travo de morbidez na outra frase a ser impressa: "o umbigo de uma pessoa morta".

Faltou dizer do vídeo posto por Cezar no sopé da escada: alguém tocando um acordeom, a se encher e esvaziar de ar como um pulmão, que, entretanto, permanece em silêncio, a não ser quando sua imagem ultrapassa os limites da tela, instante de corte que produz som: fragmentos do Hymne a I'Amour. Som entrecortado, como o ranger da escada (fole arquitetônico?) sob o peso dos corpos, que se mistura aos rumores vários da casa - sejam os imagináveis do passado doméstico ou os con- 
temporâneos da instituição cultural -, agrega-se às interferências dissonantes dos vídeos de Gisele, ao leve estalar seco das folhas de Beatriz, ao barulho do tráfego que invade todo o edifício. Soma de retalhos sonoros cujo desafio é nos acompanhar, mesmo quando formos embora, deixando para trás o portão do Castelinho (simétrico como a árvore de uma), e reverberar ainda que estejamos longe, sós sob o céu da cidade (negro como os urubus da outra), sendo capaz de impregnar-se na pesquisa de cada artista e em nossos corpos, transpondo os ruídos da desolação atual à condição de música.

\section{Calma tensão ${ }^{3}$}

Como a superfície do mar calmo, onde se tocam as riquezas submarinas e tudo que o ar envolve, a pele das obras de Amador Perez é membrana fina e suave, constituída por múltiplos gestos e traços, mais todas as gamas

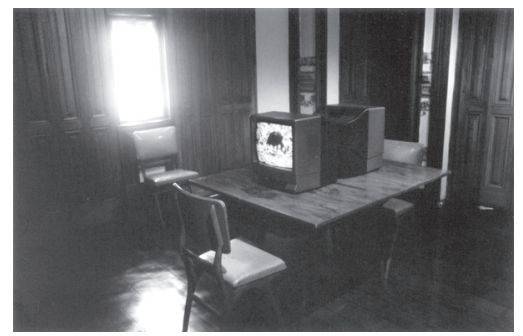

Gisele Ribeiro de cinza existentes entre a

luz e a escuridão. Essa mansidão não deve, entretanto, levar alguém a supor um fazer tranqüilo. O espelho d'água guarda tensões. O observador atento logo percebe como essa relva aquático-etérea é eriçada, apesar da meticulosa obsessão por uma precisão elegante, contida, que pouco se permite arroubos e desvairios.

Atuando no registro da música de câmara, em que a redução dos meios não significa perda de amplitude, Amador Perez força os limites do campo que traçou para si.

Além do desenho, a exploração das capacidades expressivas dos meios gráficos estendeu-se recentemente à gravura e aos meios digitais, retomando suas experiências com reprodutibilidade desenvolvidas a partir de fotocópias nos anos 1970. Ao digitalizar, esquartejar e por na cruz a Femme nue débout de dos, de Prud'hon, ensaia possibilidades outras não só quanto à técnica e à autoria, mas também de formato e escala. 
Tão cantada pelos admiradores e na fortuna crítica, a técnica é o fio-da-navalha do artista, que precisa domar a perícia, contendo o exibicionismo e revertendo a neutralidade, para fazer as imagens fluirem. Imagens que também correm riscos ao deambularem à beira do precipício da ilustração.

Jogando discretamente com o sistema de arte, calculando retiros e intervenções, o artista volta ao circuito das galerias comerciais após longa ausência. Usando a reprodutibilidade técnica também como modo de tornar seu trabalho mais acessível, inicia com as tonergrafias uma difusão do trabalho efetivamente ao alcance de seu público na qual tem o desafio de equacionar qualidade e quantidade.

Amador Perez enfrenta as dificuldades da imaginação formal na conjuntura histórica contemporânea apropriando-se de imagens, sobretudo do mundo da arte. O precedente de suas apropriações não é, contudo, a Gioconda com bigode de Duchamp, nem Warhol atualizando as cores de Matisse, muito menos Rauschenberg apagando De Kooning ou as citações díspares de Schnabel. Seu enfrentamento da história da arte é próximo da reelaboração de telas de Courbet e Velázquez feita por Picasso.

Aumentando a provocação auto-imposta, Amador Perez concentra-se ainda mais em obras-primas da história da arte, em retratos, modelos e auto-retratos de ninguém menos que Corot, Courbet, Dix, Dürer, Goya, Hogarth, Ingres, Michelangelo, Munch, Prud'hon, Rembrandt, Ticiano, Velázquez e Vermeer.

Se as telas de Picasso são embates pictóricos nos quais está em jogo a vitalidade da Pintura, Amador Perez vive os dilemas da criação na arena gráfica. Transpostas para esse universo, as formas reverberam como imagens. O artista as manipula sem pudor: rebate, duplica, apaga, soma, corta, dobra e esquadrinha, destacando e revelando componentes de sua estrutura por meio da geometria euclidiana. Abandonando a tradução ótica das qualidades táteis, explora as propriedades visuais dos meios gráficos. Mesmo quando aparecem outros timbres, a cor é gráfica, revelando a proeminência concedida à luz. Com suportes e matérias declaradamente coadjuvantes, o trabalho roça os limites mínimos da substancialidade. 
$\mathrm{Na}$ epiderme quase imaterial das obras encontram-se elementos que emergem da profundeza das imagens e projeções do artista, fundindo seus fantasmas com os da arte. Nos autoretratos, retoma distanciadamente a procura da auto-imagem. Focando na cabeça e na mão, mais detidamente no olhar e no instrumental artístico, sublinha a dicotomia entre pensamento e ação. Nos retratos e modelos, é flagrante o erotismo, latente nas delicadas linhas e manchas que bolinam a corporeidade imagética. Carícias que clamam atenção para as imagens e, sobretudo, o fazer artístico.

A onipresença de Narciso permite que sua imagem esteja ausente. À beira d’água, a mirar esses espectros, chegará a hora de mergulhar.

\section{Contrários consoantes ${ }^{4}$}

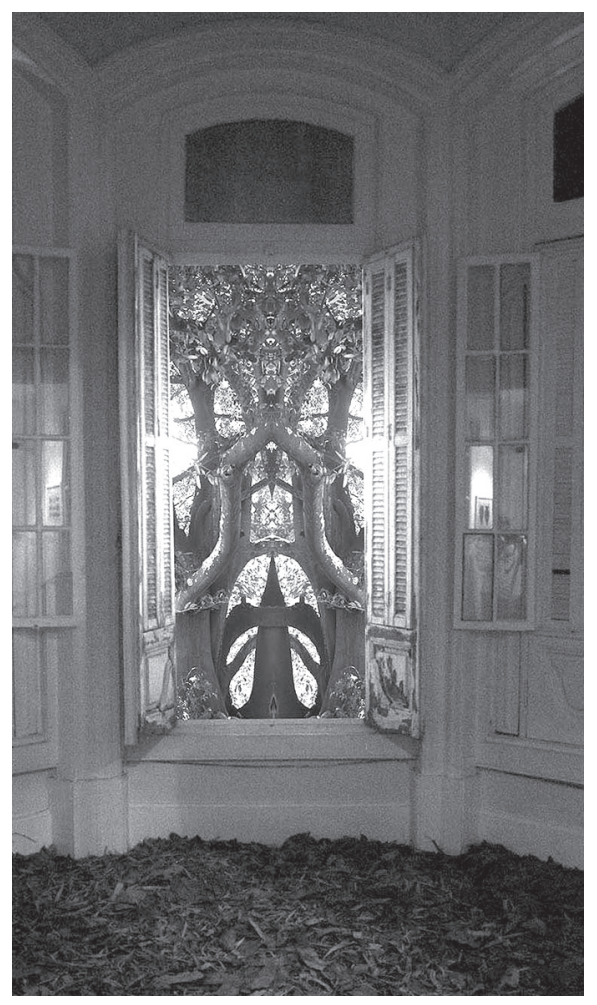

Beatriz Pimenta
Estranho ao mundo da arte (se é que ainda existe algo estranho à arte hoje, seja objeto, tema, prática ou lugar), o chiclete articula as profundezas misteriosas da Terra, o tempo imemorial das sedimentações geológicas, com a voracidade moderna de expropriação e manipulação da natureza, mais a trivialidade dos hábitos culturais na era de massas. Matéria privilegiada por Heleno Bernardi em sua "Masseter Suite", a goma de mascar permite observar um elemento chave de seu trabalho como artista: o jogo de opostos. 
São pares, trios e múltiplos em contrariedade na série. Disciplina quase obsessiva versus variedade descompromissada. Uma certa intimidade inerente à prática corriqueira de mascar chiclete em oposição à frieza fotográfica, pretensamente natural, entre as lógicas do arquivo e da propaganda. Corpo representado, moldado, em ação, avariado, residual. Cientificismo e cultura pop. Seriedade + cliché. Tensões materiais tênues contra enquadramentos rígidos. Reflexos gerando opacidade. Borracha sobre plástico, pele ou osso. Associações visuais diretas intrigadas por títulos cifrados. Manobras de sedução x efeitos repulsivos. Retiro autoral em construção de persona artística. Asco colorido; dramaticidade cor-de-rosa. E o problema da jovem decrepitude, tão pertinente nesse inicio de milênio ainda com jeito de fin de siècle.

Nas oposições, sobressai o contraste entre pessoalidade e distanciamento. Par quase onipresente no meio artístico atual, subjetivismo e cálculo insinuam-se desde o primeiro instante do trabalho. Mas a subjetividade manifesta-se menos na lembrança ou na figuração corporal do que na estratégia profissional. O projeto aparece mais nas escolhas subjetivas, na matéria e nos procedimentos eleitos, do que na conceituação. Quando se constata quão impessoal é o modo de engajamento do corpo no trabalho e com que naturalidade são acionadas as táticas de inserção e trânsito no circuito de arte, conclui-se que, em vez de se anularem, os confrontos são reiterativos e autoestimulantes. Contrários consoantes abrindo-se em múltiplas direções.

Nesse sentido, é um tanto corajosa a decisão de oferecer ao público um trabalho tão desarmado, de inserir-se no meio de arte com uma exposição assumidamente aberta e até divergente. Exibindo com franqueza e sem maiores elocubrações seus insights espertos, Heleno Bernardi deixa entrever algumas possibilidades de encaminhamento do trabalho, para além da variedade dos suportes. Pode investir em um dos pólos da pesquisa: exacerbando a pessoalidade com a exploração do corpo nos limites das práticas mundanas ou concentrando-se criticamente nas manobras artísticas. E pode radicalizar o confronto: mergulhando na sofrida ironia pop e na reflexividade conceitu- 
al, de modo a internalizá-los na vivência do projeto. Mas não deve fechar os caminhos, nem abandonar a produtividade dos conflitos.

\section{De primeira $^{5}$}

O trabalho de Rômulo Martinz é mais um indício da relatividade contemporânea dos meios técnicos na experimentação em arte. O artista pode valer-se tanto das técnicas mais recentes de produção da imagem (fotografia, cinema e meios digitais) quanto das técnicas mais tradicionais de formalização (desenho, pintura, escultura e gravura). O diferencial artístico está além.

De imediato, salta aos olhos o seu domínio dos meios gráficos, o uso

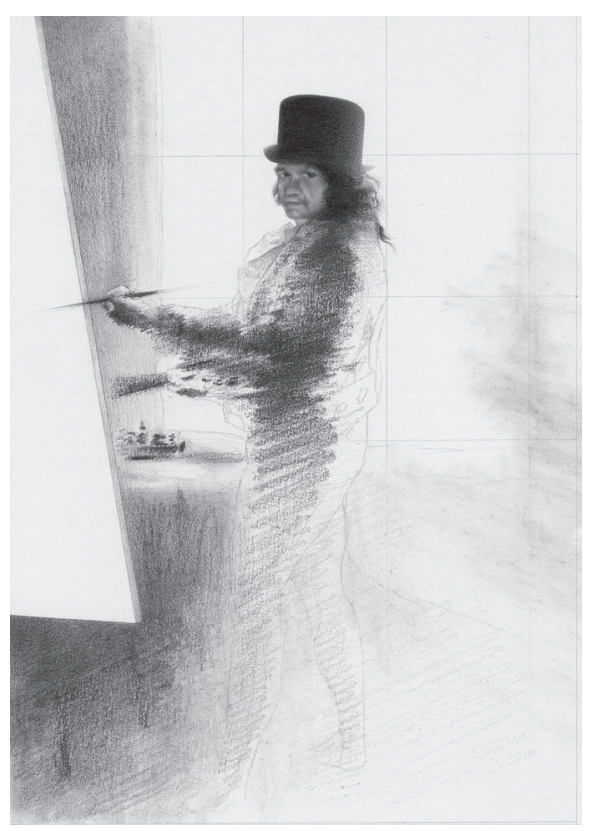

Amador Perez rigoroso e intenso de papel, tinta e grafite para deflagrar a luz em suas gradações rumo à escuridão. Logo, contudo, perbemos como as obras exploram mais do que o tonalismo luminoso. Aproximando-se da pintura, papel, tinta e grafite aparecem também como cores, como timbres específicos da luz: branco, preto e cinza. E mais - papel, tinta e grafite também conseguem ser vistos apenas enquanto tais: papel, tinta e grafite. Plurívocos e anti-ilusionistas, os desenhos falam das propriedades dos materiais, evidenciando ressonâncias de suas texturas - o brilho algo aquoso do grafite, a opacidade seca da tinta acrílica, o aveludado úmido do papel.

Atrai, também à primeira vista, o seu domínio da planaridade, o vigor com que faz pulsar a reversibilidade entre fundo e 
figura. Formas geométricas sutilmente impuras e linhas de força esgarçadas e rompidas fazem o campo latejar, contraindose e dilatando. Grades ao mesmo tempo corroídas e primevas conquistam vitalidade contemporânea para uma ordem plástica historicamente desgastada.

Poderiam ser estabelecidas conexões com movimentos artísticos anteriores e experiências atuais semelhantes. Invocar precedentes ou correlatos históricos seria, entretanto, um exercício de pedantismo sufocante na abordagem de um trabalho tão impulsivo e, em certa medida, inculto. O trabalho livre e despretensioso de Rômulo Martinz não estimula nem recomenda usar argumentos de autoridade.

Mais produtivo, me parece, é sublinhar como suas obras indicam um processo de questionamento da percepção do e no mundo. Pesquisa constante e inquieta que o levou a ampliar seu campo de ação, experimentando a pintura e o campo tridimensional. Inserindo-nos em suas explorações de reflexos, opacidades e transparências com espelhos no espaço, explicita e redimensiona o chamado para que participemos de seu interrogar, mergulhando nos mistérios e abismos do ver e dos demais sentidos humanos. 


\section{Notas}

1- Texto publicado no folheto do projeto "Acesso remoto - Entfernter Zugang", que se desdobrou nas exposições realizadas entre 21 de fevereiro e 10 de março de 2002 na Galeria Mira Schendel da Universidade Estácio de Sá, no Rio de Janeiro/RJ, Brasil, e entre 09 de abril e 04 de maio de 2002, na Galerie Maerz, em Linz, Áustria.

2- Texto publicado no folheto da exposição realizadas entre 27 de setembro e 24 de outubro de 2002 no Centro Cultural Oduvaldo Vianna Filho - Castelinho do Flamengo, no Rio de Janeiro/RJ.

3- Texto publicado no folheto da exposição "A Arte da Impressão", de Amador Perez, realizada entre 02 de outubro e 01 de novembro de 2003, na galeria Lana Botelho Artes Visuais, no Rio de Janeiro/RJ.

4- Texto publicado no folheto da série "Maseeter Suíte" de Heleno Bernardi, exposta entre 10 e 28 de novembro de 2003 na Pinacoteca de Viçosa, em Viçosa/MG.

5- Texto publicado no folheto-convite da exposição "Ambiguidade/ Casualidade", de Rômulo Martinz, realizada no Solar Grandjean de Montigny - Centro Cultural da PUC-Rio, em 18 e 19 de novembro de 2003, no Rio de Janeiro/RJ.

\section{ROBERTO CONDURU}

Historiador da arte, professor no Instituto de Artes da Universidade do Estado do Rio de Janeiro. É autor de Vital Brazil (Cosac \& Naify, 2000), coautor de A Missão Francesa (Sextante, 2003), co-organizador de Políticas Públicas de Cultura do Estado do Rio de Janeiro (Rede Sirius, 2003) e Um Modo de Ser Moderno - Lucio Costa e a Crítica Contemporânea (Cosac \& Naify, 2004), além de ensaios sobre arte e arquitetura publicados em livros, revistas e catálogos, no Brasil e no exterior. Email: rconduru@uol. com.br 